\title{
Hyperlink network analysis of a multi destination region: the case of Halland, South Sweden
}

\author{
Fanni Zoé Éber ${ }^{1} \cdot$ Rodolfo Baggio $^{2,3} \cdot$ Matthias Fuchs $^{1}$ (D)
}

Received: 15 February 2018 / Accepted: 1 March 2018 / Published online: 7 March 2018

(C) The Author(s) 2018. This article is an open access publication

\begin{abstract}
Over the past years, attention has been given to the relevance of network studies as an analytical tool to assess essential features of a tourism destination. This work analyzes the network of Halland County, a tourism destination in South Sweden. The study aims at enhancing the body of knowledge and the comprehension of the structural characterization of the tourism network, deriving indications for policy makers and local stakeholders in order to improve the effectiveness and efficiency of the regional tourism system. Tourism stakeholders' websites were explored using hyperlink network analysis (Baggio in Phys A 379(2):727-734, 2007; Raisi et al. in J Travel Res https://doi.org/10.1177/0047287517708256, 2017). Findings highlight the need for strengthened industry ties and contribute to the industry-wide discussion on exploring network topology as a key source of knowledge for destination management and development, respectively.
\end{abstract}

Keywords Hyperlink network analysis · Multi destination region · Tourism websites · South Sweden

Matthias Fuchs

matthias.fuchs@miun.se

Fanni Zoé Éber

fanni_zoe@hotmail.com

Rodolfo Baggio

rodolfo.baggio@unibocconi.it

1 Department of Tourism Studies and Geography, Mid-Sweden University, Kunskapens Väg 1, 83125 Östersund, Sweden

2 Bocconi University, Milan, Italy

3 National Research Tomsk Polytechnic University, Tomsk, Russia 


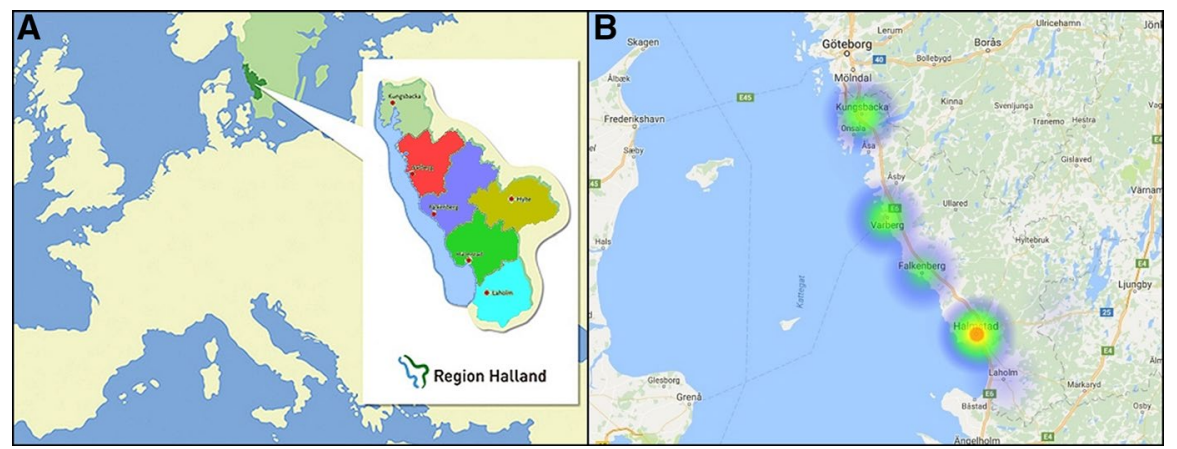

Fig. 1 The Halland County, Sweden, with its six tourism destination areas (a); and the distribution of tourist flows (b)

\section{Introduction}

The identification of a destination's network is particularly important for uncovering patterns of cooperation and collaboration in a destination. To this extent, a methodological approach that has gained attention in the last years is the analysis of the networks of connections between the stakeholders of a destination. While an increasing number of works has been devoted to the understating of the structural characterization of single destination areas, the networks of multiple areas have not yet been extensively explored (Baggio 2017; van der Zee and Vanneste 2015).

This work reports on preliminary findings from a network analysis conducted in a wider framework that aims at developing a strategy for the Halland County, a developing Swedish tourism region consisting of six destination areas. By doing so, the study contributes to the existing tourism network literature showing a case of multiple destination areas.

\section{Materials and methods}

Halland County (Fig. 1a) comprises six municipalities that stretch on the southwestern coast of Sweden over an area of about $5500 \mathrm{~km}^{2}$ (roughly $1.2 \%$ of Sweden's total area). Outdoor recreational areas, camping and beaches are of great importance for the destination's economy. The area's diverse nature-attractive beaches, forests, and inland lakes - attracts a large number of visitors every year. In particular, the four rivers that cross the county are an important source for local fishing businesses, also devoted to sport fishing by both domestic and international tourists.

Over the last 10 years, the Halland County averages 2.5 million overnight stays (Statistics Sweden 2017), with a strong seasonality (i.e. seasonality index $=3.63$, as the difference between the highest monthly value and the average annual value). A presence of domestic tourists is strongly predominant (87.8\%). From the perspective of the tourism area lifecycle (Butler 2006a, b), Halland County is at an initial stage 

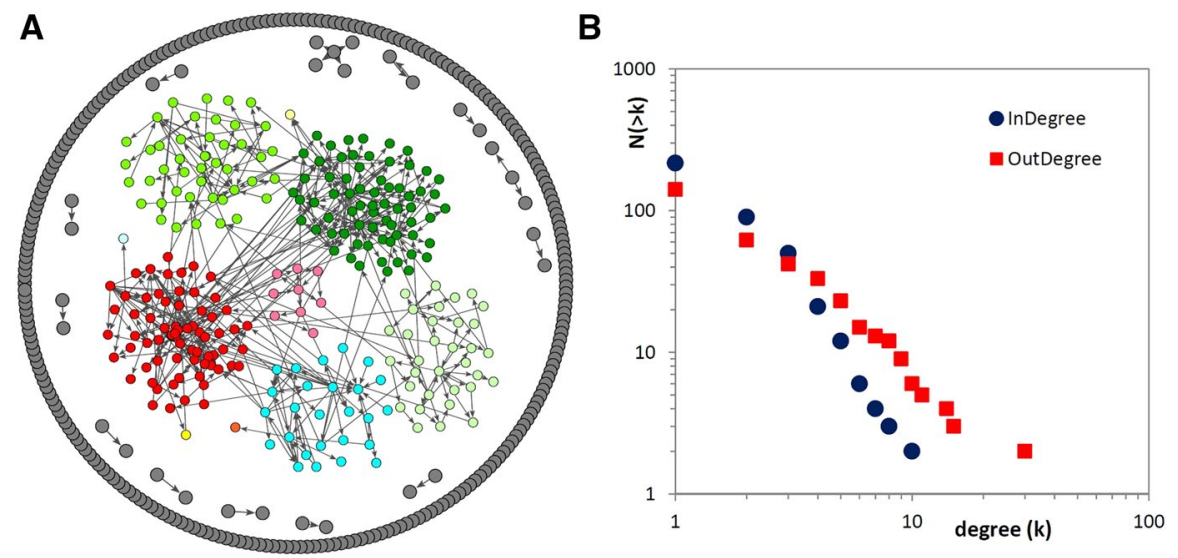

Fig. 2 The network graph of Halland County (a); and the cumulative degree distributions (b)

of tourism development. This stage is dominated by small and medium-sized businesses unevenly spread throughout the various municipalities (Fig. 1b).

As shown in previous studies (Park and Thelwall 2003; Baggio et al. 2010; Baggio and Del Chiappa 2014; Ying et al. 2016; Raisi et al. 2017), the hyperlinks of tourism organizations' websites are a good indicator for the configuration of the real-world relationships (links) between destination stakeholders. Thus, network data used in this work considers the websites belonging to tourism-related organizations and businesses in the Halland County as the elements (nodes) of the regional tourism network. The data file comprising all 738 tourism-related businesses and organization was obtained from the regional tourism authority, Halland Destination.

Although, compared to other similar studies, network size is relatively small (Ying et al. 2016; Raisi et al. 2017), it can be considered sufficient to analyze the topology of the underlying tourism network, thus, to provide meaningful empirical insights (Newman 2003). The analysis was conducted at three levels: macro (i.e. the global properties of the network), meso (i.e. the intermediate structure of the network), and micro (i.e. the characteristics of the most prominent actors). For their full definitions and further methodological discussions, the interested reader can consult the general network science literature (e.g. da Fontoura Costa et al. 2007; Baggio et al. 2010; Newman 2003, 2010). All results reported here are normalized (i.e. bound within $[0,1])$ for easier interpretation.

\subsection{The macroscopic network structure}

After manually examining 3505 hyperlinks, the regional tourism network consists of 535 websites of tourism-related organizations (nodes) and 406 links. The (directed) network graph of the Halland County is visualized in Fig. 2a. Its network density is extremely low (0.0014), indicating a very sparse network, with a substantial proportion of isolated nodes: $52.1 \%$. This sparseness is further confirmed by the small value of the average clustering coefficient, an indicator of local density (0.006). 
Likewise, the global efficiency, defined as the capacity to transfer information across the network, is very low (0.0029). Furthermore, the assortativity coefficient (i.e. the correlation between an node's degree and those of its neighbors) is -0.052 , indicating a slightly negative tendency for an actor to connect to others with low degrees. Both, clustering and assortativity coefficients show a poor inclination to form collaborative and cooperative groups (Baggio 2007; Raisi et al. 2017). Moreover, these metrics (mainly assortativity) indicate a low resilience of the system (Newman 2002; Noldus and Van Mieghem 2015). In line with Butler's (Butler 2006a, b) tourism area lifecycle framework, this situation can be interpreted as a natural consequence of an early stage of destination's development that has not yet built a solid network structure among tourism stakeholders.

Similar to previous studies (Baggio and Del Chiappa 2014; Ying et al. 2016; Raisi et al. 2017), the degree distributions (in-degree and out-degree) follow a power-law with exponents: in-degree $=3.50 \pm 0.58$ and out-degree $=1.96 \pm 0.34$ (Fig. 2b). The marked difference in the two values indicates a greater dispersion and tendency to connect different actors, while receiving fewer and well-concentrated links (da Fontoura Costa et al. 2007). Similarly, this empirical finding can be interpreted as an indication of first attempts at establishing strong structural ties among regional tourism stakeholders at an early stage of the tourism area lifecycle (Butler 2006a). In any case, the power-law patterns are signaling a high concentration of links, with a few elements (nodes) of the network controlling, de facto, the entire regional tourism system. Again, this can be seen as a symptom of early stages of tourism development (Butler 2006b).

The topological structure of the World Wide Web has been studied by many researchers. The bow-tie structure model, first proposed by Broder et al. (2000), shows that a general WWW network displays six components:

- SCC: strongly connected components; the central core, "all of whose pages can reach one another along directed links" (Broder et al. 2000, p. 310).

- IN: web pages that are connected to SCC, but unreachable from SCC, as these sites are yet undiscovered in the network.

- OUT: web pages accessible from SCC, but do not link back to it.

- TUBES: web pages linking to IN or OUT pages without crossing SCC.

- TENDRILS: pages that can be reached from, or can reach IN and OUT, but have no links to SCC.

- DCC: disconnected components.

The main rationale for conducting a bow-tie analysis for a hyperlink network analysis purpose is to provide a clearer view of the tourism network connectivity as a whole (Raisi et al. 2017). As the results in Fig. 3 and Table 1 indicate, the largest component is disconnected components (DCC), followed by TENDRILLS, while the number of web pages related to strongly connected components (SCC), IN, and TUBES, is extremely small.

To conclude, there are numerous outside-oriented relationships within this destination network, which is clear evidence for the relatively low level of cooperation and collaboration between local tourism businesses. The bow tie structure analysis 


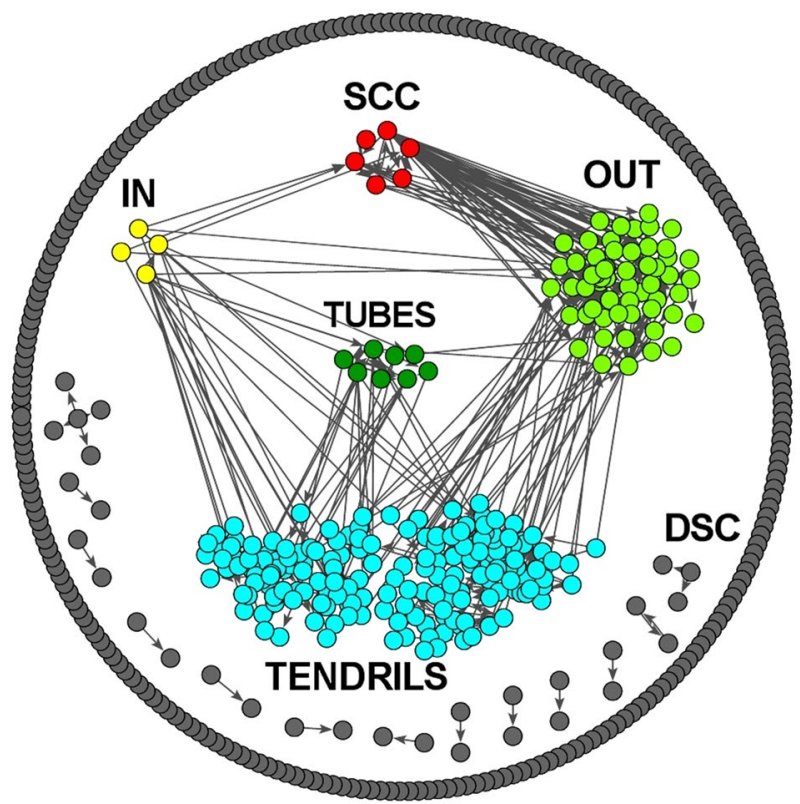

Fig. 3 The Bow-tie graph of Halland County

Table 1 Bow-tie components

\begin{tabular}{lcr}
\hline Components & Node \# & $\%$ \\
\hline SCC & 6 & 1.12 \\
IN & 4 & 0.75 \\
OUT & 59 & 11.03 \\
TUBES & 8 & 1.50 \\
TENDRILS & 179 & 33.45 \\
DSC & 279 & 52.15 \\
\hline
\end{tabular}

clearly shows the components' tendency to connect out from the core components. The above analysis of the in-, and out-degree distribution (Fig. 2b) provided further evidence to this phenomenon: the out-degree shows a lower exponent than the indegree, which is an additional indication of network members' tendency to refer to other members out of the region, rather than within the local or regional network, respectively (da Fontoura Costa et al. 2007).

\subsection{The mesoscopic network structure}

Figure 2a also shows an interesting characteristic of the network's mesoscopic structure. A relatively small central connected component (47.8\%) made of well-defined clusters (communities) that reflect the municipalities of the County (colors are by 
municipality). The modularity index $\mathrm{Q}$, measuring the extent to which this subnetwork is divided into communities is $Q=0.739 .{ }^{1}$ At a first sight, this seems to be in contradiction with the idea of poor collaborative attitudes. However, if we consider the whole regional network and normalize this value to the number of communities and by also taking into account the fraction of disconnected nodes, we obtain a significantly lower value, $\mathrm{Q}=0.167$, thus, reconfirming our previous deductions. It is important, again, to notice that at this early stage of the tourism area lifecycle (Butler 2006a), a combined destination is practically non-existent, although, initial seeds can be identified.

\subsection{The microscopic network structure}

Finally, on a microscopic level, we highlighted the most influential nodes in the network. As in Sainaghi and Baggio (2014), we considered an 'importance index', defined as the geometric mean of the various (i.e. normalized) centrality metrics, such as degree, eigenvector, clustering coefficient, betweenness and closeness (da Fontoura Costa et al. 2007). Interestingly enough, organizations involved in cultural and sporting activities are dominating the ranking (Table 2). This is a promising element for the prosperity and future development of this destination area, as these particular tourism and leisure activities are strongly bound to the features of this Swedish region, thus, are of high importance for developing and strengthening the destination brand (Chekalina et al. 2014, 2018).

\section{Concluding remarks}

The analyzed virtual tourism network of Halland County, Sweden, shows structural characteristics relatively similar to those of previous destination network studies (Baggio 2017; Raisi et al. 2017; van der Zee and Vanneste 2015; Ying et al. 2016). However, its topology seems rather sparse. In this particular case, the inspection of a composite destination highlights the early stage of its development, as only initial attempts to form inter-municipality connections are empirically identified (Butler 2006a). Thus, beyond valuable insights regarding most influential and important destination stakeholders, the proposed network analysis approach provides a good indication for policy makers in suggesting to create a sounder cooperative environment (McDonald 2009; Eagle et al. 2010; Feldman 2014; Baggio et al. 2016). The latter includes all of the destination areas, thus, strengthening the possibility to prosper in a balanced way, thereby creatively exploiting the combined attractiveness of the natural and cultural resources available (Gibson et al. 2005; Loorbach 2010; Fuchs and Baggio 2017). Being a preliminary analysis, and a first step of a wider and deeper study, this work is obviously limited mainly in that it needs further confirmations and cross-validation. The latter will come from a series of inquiries

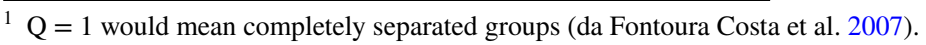


Table 2 Top 30 most influential organizations ranked by importance index

\begin{tabular}{|c|c|c|c|c|}
\hline Rank & Imp. index & Name & Type & Municipality \\
\hline 1 & 0.031 & Berte Museum & Museum & Falkenberg \\
\hline 2 & 0.031 & Atelje Grimsten & Tourist services & Falkenberg \\
\hline 3 & 0.025 & Ugglarps Camping & Camping site & Falkenberg \\
\hline 4 & 0.023 & Skogaby Golf & Golf club & Laholm \\
\hline 5 & 0.023 & Thai Royal & Restaurant & Falkenberg \\
\hline 6 & 0.022 & Gekåsbyn Ullared & Camping site & Falkenberg \\
\hline 7 & 0.022 & Vallåsen Fritidsanläggning & Ski facilities & Laholm \\
\hline 8 & 0.022 & Falkeergs Kommun & Museum & Falkenberg \\
\hline 9 & 0.021 & Halmstad Äventyrland & Museum & Halmstad \\
\hline 10 & 0.020 & Falkenergs Fotbollsförening & Sport club & Falkenberg \\
\hline 11 & 0.019 & Äppelgården Café and Atelje & Restaurant & Falkenberg \\
\hline 12 & 0.018 & Hotell Halland & Hotel & Kungsbacka \\
\hline 13 & 0.018 & Tiraholms Fisk & Restaurant & Hylte \\
\hline 14 & 0.018 & Hylte Kommun & Sport facilities & Hylte \\
\hline 15 & 0.017 & Stiftelsen Tjolöhom & Restaurant & Kungsbacka \\
\hline 16 & 0.017 & Hotell Hovgård & Hotel & Halmstad \\
\hline 17 & 0.016 & Ringenäs Golf & Golf club & Halmstad \\
\hline 18 & 0.016 & Grand Hotell I Falkenberg & Hotel & Falkenberg \\
\hline 19 & 0.015 & Orbit Outdoors & Hostels & Halmstad \\
\hline 20 & 0.014 & Vabergs Kommun & Recreation facilities & Varberg \\
\hline 21 & 0.013 & Swedcamp and Hertings Bad Kontor & Hotel & Falkenberg \\
\hline 22 & 0.013 & Torups Gästgivarengård & Hotel & Hylte \\
\hline 23 & 0.011 & Falkenbergs Motorklubb & Sport club & Falkenberg \\
\hline 24 & 0.009 & Laholms Vandrarhem & Hostels & Laholm \\
\hline 25 & 0.009 & Grötviks Segelsällskap & Sport club & Halmstad \\
\hline 26 & 0.009 & Halmstad Gold Arena & Sport facilities & Halmstad \\
\hline 27 & 0.008 & Avgång Halmstad & Travel agency & Halmstad \\
\hline 28 & 0.008 & Aktiebolaget Haverdals Golf & Golf club & Halmstad \\
\hline 29 & 0.008 & Bryggcaféet Götvik & Restaurant & Halmstad \\
\hline 30 & 0.005 & Relax Fishing & Sport facilities & Laholm \\
\hline
\end{tabular}

covering both, the quantitative and qualitative aspects of the problem, and can, ultimately, lead to a sound strategic development plan for the Halland County and other destinations.

Open Access This article is distributed under the terms of the Creative Commons Attribution 4.0 International License (http://creativecommons.org/licenses/by/4.0/), which permits unrestricted use, distribution, and reproduction in any medium, provided you give appropriate credit to the original author(s) and the source, provide a link to the Creative Commons license, and indicate if changes were made. 


\section{References}

Baggio R (2007) The web graph of a tourism system. Phys A 379(2):727-734

Baggio R (2017) Network science and tourism - the state of the art. Tour Rev 72(1):120-131

Baggio R, Del Chiappa G (2014) Real and virtual relationships in tourism digital ecosytems. Inf Technol Tour 14(1):3-19

Baggio R, Scott N, Cooper C (2010) Network science-a review focused on tourism. Ann Tour Res 37(3):802-827

Baggio R, Moretti V, Fuchs M (2016) Beauty and creativity and their role in fostering economic and social development. In: Laven D, Skoglund W (eds) Valuing and evaluating creativity for sustainable regional development, VEC-UNESCO conference, 11-14 Sept. Mid-Sweden Univeristy, Östersund, Sweden, pp 157-159

Broder A, Ravi K, Farzin M, Prabhakar R, Sridhar R, Raymie S, Tomkins A, Wiener J (2000) Graph structure in the web. Comput Netw 33(1):309-320

Butler RW (2006a) The tourism area life cycle-applications and modifications, vol 1. Channelview Publications, Clevedon

Butler RW (2006b) The tourism area life cycle-conceptual and theoretical issues, vol 2. Channelview Publications, Clevedon

Chekalina T, Fuchs M, Lexhagen M (2014) A value creation perspective on the customer-based brand equity model for tourism destinations - a case from Sweden. Finn J Tour Res 10(1):7-23

Chekalina T, Fuchs M, Lexhagen M (2018) Customer-based destination brand equity modelling-the role of destination resources, value-for money and value-in-use. J Travel Res 57(1):31-51

da Fontoura Costa L, Rodrigues A, Travieso G, Villas Boas PR (2007) Characterization of complex networks: a survey of measurements. Adv Phys 56(1):167-242

Eagle N, Macy M, Claxton R (2010) Network diversity and economic development. Science 328(21):1029-1031

Feldman MP (2014) The character of innovative places. Small Bus Econ 43(1):9-20

Fuchs M, Baggio R (2017) Creativity and tourism networks-a contribution to a post-mechanistic economic theory. In: Paper presented at: critical tourism studies, understand tourism-change tourism-understand ourselves - change ourselves, 25-29 June, Palma de Mallorca, Spain

Gibson L, Lynch PA, Morrison A (2005) The local destination tourism network: development issues. Tour Hosp Plan Dev 2(2):87-99

Loorbach D (2010) Transition management for sustainable development: a prescriptive, complexitybased governance framework. Govern Int J Policy Adm Inst 23(1):161-183

McDonald JR (2009) Complexity science: an alternative world view for understanding sustainable tourism development. J Sustain Tour 17(4):455-471

Newman MEJ (2002) Assortative mixing in networks. Phys Rev Lett 89(20):208701

Newman MEJ (2003) The structure and function of complex networks. Soc Ind Appl Math 45(2):167-256

Newman MEJ (2010) Networks-an introduction. Oxford University Press, Oxford

Noldus R, Van Mieghem P (2015) Assortativity in complex networks. J Complex Netw 3(4):507-542

Park HW, Thelwall M (2003) Hyperlink analyses of the World Wide Web: a review. J Comput Med Commun, 8(4). http://jcmc.indiana.edu/vol8/issue4/park.html. Accessed March 2006 (online)

Raisi H, Baggio R, Barratt-Pugh L, Willson G (2017) Hyperlink network analysis of a tourism dstination. J Travel Res. https://doi.org/10.1177/0047287517708256

Sainaghi R, Baggio R (2014) Structural social capital and hotel performance: is there a link? Int J Hosp Manag 37:99-110

Statistics Sweden (2017) Statistiska Centralbyrån-SCB. http://www.statistikdatabasen.scb.se/pxweb/en/ ssd/START_NV_NV1701_NV1701B/NV1701T910M/?rxid=95a5311d-9471-480f-aca3-109ee cb24194. Accessed Oct 2017

van der Zee E, Vanneste D (2015) Tourism networks unravelled; a review of the literature on networks in tourism management studies. Tour Manag Perspect 15:46-56

Ying T, Norman WC, Zhou Y (2016) Online networking in the tourism industry a webometrics and hyperlink network analysis. J Travel Res 55(1):16-33 